\title{
Transfer Fonologis Konsonan Hambat dari Bahasa Jawa ke Bahasa Indonesia
}

\author{
Rosalin Ismayoeng Gusdian \\ Universitas Muhammadiyah Malang \\ rosalingusdian@umm.ac.id
}

\begin{abstract}
Abstrak
Penelitian ini bertujuan untuk mendeskripsikan transfer fonologis konsonan hambat yang terjadi dari Bahasa Jawa ke Bahasa Indonesia. Penelitian ini menggunakan metode penelitian kualitatif guna mengetahui transfer fonologis apa saja yang ditemukan saat penutur Bahasa Indonesia yang memiliki aksen Jawa mengucapkan kata-kata yang mengandung konsonan hambat di dalam Bahasa Indonesia. Subjek penelitian ini adalah 5 orang penutur Bahasa Indonesia dengan aksen Jawa. Selanjutnya, kelima subjek diberi sebuah cerita pendek yang memuat kata-kata dengan konsonan hambat; kemudian, suara mereka direkam. Dari hasil analisis data, ditemukan bahwa terdapat perbedaan beberapa konsonan hambat Bahasa Jawa dan Bahasa Indonesia yang termuat dalam transfer fonologis yang diucapkan oleh penutur Bahasa Indonesia beraksen jawa. Beberapa transfer tersebut antara lain transfer konsonan plosif kendur bersuara, substitusi untuk konsonan berhenti velar [k] menjadi suara glottal [?] pada koda (akhir kata), dan substitusi untuk konsonan frikatif labio-dental [f] menjadi konsonan bilabial tak bersuara [p].
\end{abstract}

Kata Kunci: konsonan hambat; bahasa jawa; bahasa indonesia

\begin{abstract}
This study aims at describing phonological transfers of stop consonant that occurs from Javanese to Indonesian. This research uses descriptive qualitative research method to reveal what phonological transfers found when speakers of Bahasa Indonesia who have a Javanese accent utter words containing stop consonants in Bahasa Indonesia. The subjects of this study were 5 speakers of Indonesian with Javanese accent. Furthermore, the five subjects were given a short story that contained words with stop consonants; then, their voices were recorded. From the results of data analysis, it was found that there are differences in some of the consonants of Java and Bahasa Indonesia contained in phonological transfers spoken by speakers of Indonesian with Javanese accent. Some of these transfers include transfer of slack voiced plosive consonants, substitutions for velar stop consonants [k] into Javanese glottal voices [?] in coda (end of word), and substitution for labio-dental fricative [f] consonants into voiceless bilabials [ $\mathrm{p}$ ].
\end{abstract}

Keywords: stop consonant; javanese; indonesian 


\section{PENDAHULUAN}

"Bahasa Indonesia", atau yang biasa disebut Bahasa, adalah bahasa resmi Republik Indonesia. Bahasa ini termasuk dalam keluarga bahasa Austronesia yang tersebar di seluruh kawasan Asia Tenggara dan Pasifik. Bahasa Indonesia telah menyatukan 480 bahasa lokal di seluruh negeri sejak 1928 (Chaer \& Agustina, 2004).

Meskipun Bahasa Indonesia adalah bahasa resmi, pada kenyataannya hanya sejumlah kecil orang Indonesia yang menggunakannya sebagai bahasa pertama mereka dalam percakapan sehari-hari. Sebaliknya, mayoritas orang Indonesia menggunakannya sebagai bahasa kedua mereka dalam situasi formal. Hal ini wajar karena Indonesia adalah negara kepulauan yang luas dengan berbagai macam etnis yang berbeda dan memiliki bahasa pertama yang berbeda pula. Karena Bahasa Indonesia digunakan bersamaan dengan penggunaan bahasa ibu dari masing-masing pembicara, kemungkinan akan terjadinya fenomena bahwa pembicara membawa beberapa aspek bahasa lokal saat menggunakan Bahasa Indonesia sudah pasti tidak dapat dielakkan. Fenomena ini disebut transfer lintas bahasa (cross-linguistic transfer), di mana pengetahuan seseorang tentang suatu bahasa memengaruhi pengetahuan seseorang atau penggunaan bahasa lainnya (Jarvis \&Pavlenko, 2008: 1). Selanjutnya, CelceMurcia (1996) menyebutkan bahwa terdapat beberapa jenis transfer lintas bahasa yang kerap kali terjadi, antara lain transfer sintaksis, morfologis, dan fonologis.

Beberapa studi telah mempelajari tentang terjadinya transfer lintas bahasa yang terjadi pada penutur Bahasa Indonesia yang dipengaruhi oleh pengetahuan mereka tentang Bahasa lain-baik bahasa daerah maupun bahasa internasional lainnya. Beberapa studi tersebut antara lain Lestiono dan Gusdian (2017a); Lestiono dan Gusdian (2017b); Mathew (2003); dan Dardjowidjojo (2009).

Sementara itu, salah satu transfer yang sering dilakukan oleh penutur bahasa lokal saat menggunakan Bahasa Indonesia adalah transfer fonologis. Jarvis \& Pavlenko (2008: 62) lebih lanjut menjelaskan bahwa transfer fonologis mengacu pada cara di mana pengetahuan seseorang tentang sistem suara dalam satu bahasa dapat mempengaruhi persepsi orang tersebut dan produksi bunyi ujaran dalam bahasa lain. Fenomena transfer fonologis penutur bahasa lokal ke Bahasa Indonesia akhirnya menghasilkan munculnya berbagai aksen dalam Bahasa Indonesia.

Salah satu aksen utama dalam Bahasa Indonesia adalah aksen Jawa, yang digunakan oleh orang-orang Jawa, suku terbesar di Indonesia. Bahasa Jawa berasal dari akar bahasa yang identik dengan Bahasa Indonesia sebagai keluarga bahasa Austronesia (Dardjowidjojo,2009). Maka, tidak heran jika banyak karakteristik yang serupa dapat ditemui di kedua bahasa tersebut.

Akan tetapi, Bahasa Jawa memiliki beberapa bunyi ujaran khas yang berbeda dari Bahasa Indonesia, dimana beberapa bunyi ujaran memiliki cara unik tersendiri untuk diucapkan. Salah satu perbedaan utama dari bunyi ujaran antara Bahasa dan Jawa terjadi dalam konsonan hambat. Dalam hal tempat artikulasi, konsonan Bahasa Jawa mengandung lebih banyak jenis konsonan hambat (stop consonant), seperti bilabial, 
alveolar, alveo-palatal, velar, retrofleksi, dan glottal; sedangkan, Bahasa Indonesia hanya terdiri dari bilabial, alveolar, alveo-palatal, dan velar hambat (Davenport \& Hannah, 2010). Selain itu, konsonan-konsonan yang disuarakan dalam bahasa Jawa dicirikan oleh suara yang kendur, suatu keadaan di mana pita suara bergetar lebih kendor daripada getaran biasa (Ladefoged \& Maddieson, 1996: 48). Karena perbedaan tersebut, orang Jawa sering membawa cara mereka menghasilkan konsonan berhenti Jawa ketika mereka mengucapkan kata-kata dalam Bahasa Indonesia, yang akhirnya menjadi ciri utama aksen Jawa dalam Bahasa Indonesia.

Menurut Davenport \& Hannah (2010) dalam produksi bunyi ujaran, konsonan hambat atau plosif diartikulasikan dengan penutupan lengkap di rongga vokal, sehingga menghasilkan penyumbatan aliran udara dari keluar melalui mulut. Konsonan hambat sendiri memiliki sub-tipe yang disebut afrikat, dimana pelepasan aliran udara termodifikasi sedemikian rupa sebagai hasil frikasi saat dikeluarkan. Dengan kata lain, bunyi afrikat diproduksi seperti bunyi plosif/hambat, dan dikeluarkan seperti bunyi frikatif.

Dalam Dardjowidjojo (2009), disebutkan bahwa Bahasa Indonesia memiliki 22 bunyi konsonan. Dari keseluruhan konsonan tersebut, terdapat 8 konsonan yang termasuk dalam konsonan hambat. Konsonan-konsonan tersebut diilustrasikan pada tabel berikut ini.

\begin{tabular}{|c|c|c|}
\hline $\begin{array}{c}\text { Konsonan } \\
\text { Hambat }\end{array}$ & $\begin{array}{c}\text { Keadaan Pita } \\
\text { Suara }\end{array}$ & Simbol \\
\hline \multirow{2}{*}{ Bilabial } & $\begin{array}{c}\text { Tak Bersuara } \\
\text { Bersuara }\end{array}$ & {$[\mathrm{p}]$} \\
& {$[\mathrm{b}]$} \\
\hline \multirow{2}{*}{ Alveolar } & Tak Bersuara & {$[\mathrm{t}]$} \\
& Bersuara & {$[\mathrm{d}]$} \\
\hline \multirow{2}{*}{ Velar } & Tak Bersuara & {$[\mathrm{k}]$} \\
& Bersuara & {$[\mathrm{g}]$} \\
\hline
\end{tabular}

\begin{tabular}{|c|c|c|}
\hline Afrikat & & \\
\hline \multirow{2}{*}{ Alveo-Palatal } & Tak Bersuara & {$[\mathrm{t}]$} \\
& Bersuara & $[\mathrm{d}]]$ \\
\hline
\end{tabular}

Tabel 1 Konsonan Hambat dalam Bahasa Indonesia

Pada tabel diatas, dapat dilihat dengan jelas bahwa dalam kaitannya dengan tempat artikulasi, cara artikulasi, dan keadaan pita suara, Bahasa Indonesia memiliki tiga pasang konsonan hambat, antara lain $[\mathrm{p}],[\mathrm{b}],[\mathrm{t}],[\mathrm{d}]$, [k], dan [g]. Selain itu, terdapat juga satu pasang afrikat, yakni afrikat tak bersuara [t $]$ dan afrikat bersuara [dz].

Jenis-jenis konsonan hambat dalam Bahasa Jawa dapat dilihat pada tabel 2 berikut ini.

\begin{tabular}{|c|c|c|}
\hline $\begin{array}{c}\text { Konsonan } \\
\text { Hambat }\end{array}$ & $\begin{array}{c}\text { Keadaan Pita } \\
\text { Suara }\end{array}$ & Simbol \\
\hline \multirow{2}{*}{ Bilabial } & $\begin{array}{c}\text { Tak Bersuara } \\
\text { Suara Kendur }\end{array}$ & $\begin{array}{c}{[\mathrm{p}]} \\
{[\mathrm{b}]}\end{array}$ \\
\hline \multirow{2}{*}{ Alveolar } & $\begin{array}{c}\text { Tak Bersuara } \\
\text { Suara Kendur }\end{array}$ & $\begin{array}{c}{[\mathrm{t}]} \\
{[\mathrm{d}]}\end{array}$ \\
\hline \multirow{2}{*}{ Velar } & Tak Bersuara & {$[\mathrm{k}]$} \\
& Suara Kendur & {$[\stackrel{\circ}{\mathrm{g}}]$} \\
\hline \multirow{2}{*}{ Retroflex } & Suara Kendur & {$[\mathrm{d}]$} \\
& Tak Bersuara & {$[\mathrm{t}]$} \\
\hline Glottal & Tak Bersuara & {$[\mathrm{?}]$} \\
\hline Afrikat & & \\
\hline \multirow{2}{*}{ Alveo-Palatal } & Tak Bersuara & {$[\mathrm{t}]$} \\
& Suara Kendur & {$[\mathrm{d} \tilde{3}]$} \\
\hline
\end{tabular}

Tabel 2. Konsonan Hambat dalam Bahasa Jawa

Dari tabel diatas, dapat diamati bahwa konsonan hambat dalam Bahasa Jawa umumnya memiliki kesamaan dengan bunyi konsonan hambat dalam Bahasa Indonesia. Namun demikian, konsonan hambat bersuara dalam Bahasa Jawa lazimnya tidak sebenarnya disuarakan karena pita suara bergetar kurang leluasa daripada getaran biasa yang disuarakan; suara yang dihasilkan dalam keadaan ini disebut dengan suara kendur. berdasarkan keadaan pita suara, konsonan hambat dalam bahasa Jawa sendiri terdiri dari 
empat pasang suara tak bersuara dan suara kendur. Karakteristik ini akhirnya menjadi ciri khas utama konsonan hambat Bahasa Jawa yang membedakannya dengan konsonan hambat dalam Bahasa Indonesia. Selain itu, konsonan glottal [?] yang muncul dalam Bahasa Jawa juga menandai perbedaan antara kedua bahasa tersebut.

\section{METODE}

Subjek penelitian ini adalah 5 orang penutur Bahasa Indonesia dengan aksen Jawa (secara khusus Jawa Timuran). Kelima orang tersebut memiliki rentang usia antara 20 sampai 22 tahun dan berasal dari beberapa kota di Jawa Timur, antara lain Malang (2 orang), Surabaya (2 orang) dan Tulungagung (1 orang). Untuk menghindari terjadinya bias jender, kelima orang tersebut terdiri dari 3 pria dan 2 wanita. Selanjutnya, para subjek disodori sebuah cerita pendek yang memuat kata-kata dengan konsonan hambat. Lalu para subjek melafalkan cerita tersebut dan suara mereka direkam menggunakan perekam suara.

Pendekatan kualitatif digunakan dalam penelitian ini, dimana data yang didapatkan dianalisis untuk mengetahui transfer fonologis apa saja yang ditemukan saat penutur Bahasa Indonesia yang memiliki aksen Jawa mengucapkan kata-kata yang mengandung konsonan hambat di dalam Bahasa Indonesia. Selain itu, hasil analisis diserahkan kepada seorang ahli fonologis untuk divalidasi.

\section{HASIL DAN PEMBAHASAN}

Secara umum, konsonan hambat dalam Bahasa Indonesia dan Bahasa Jawa memiliki banyak kemiripan. Hal ini tidak mengherankan karenan kedua bahasa tersebut berasal dari rumpun bahasa yang sama, yakni rumpun bahasa Austronesia. Salah satu persamaan dari kedua bahasa tersebut secara fonologis adalah kedua bahasa tersebut samasama memiliki konsonan hambat tak bersuara seperti $[\mathrm{p}]$, [t], dan [k].

Namun, terlepas dari kenyataan bahwa kedua bahasa mengandung beberapa kesamaan dalam konsonan hambat, perbedaan juga dapat ditemukan dalam beberapa aspek lain dari konsonan hambat dari kedua bahasa tersebut. Dalam penelitian ini, ditemukan bahwa perbedaan beberapa konsonan hambat Bahasa Jawa dan Bahasa Indonesia terefleksikan dalam transfer fonologis yang diucapkan oleh penutur Bahasa Indonesia beraksen jawa. Beberapa transfer tersebut antara lain transfer konsonan hambat bersuara kendur, substitusi untuk konsonan berhenti velar [k] menjadi suara glottal Jawa [?] di koda (akhir kata), dan substitusi untuk konsonan frikatif labio-dental [f] menjadi konsonan bilabial tanpa suara [p]. Lebih jauh pembahasan dari setiap transfer adalah sebagai berikut:

\section{Transfer Konsonan Jawa Bersuara Kendur}

Ciri dari konsonan hambat dalam Bahasa Indonesia adalah terjadinya penyumbatan total dalam saluran suara yang menghasilkan hambatan aliran udara yang melewati mulut. Selain itu, karena terdapat kontraksi otot antara pita suara, maka aliran udara mendorong pita suara hingga bergetar, dan akhirnya getaran tersebut menghasilkan suara. Konsonan hambat bersuara biasanya terjadi pada posisi awal kata atau pada onset suku kata. Sementara itu, Hampir mirip dengan Bahasa Indonesia, konsonan hambat bersuara 
kendur dalam Bahasa Jawa juga diilustrasikan dengan adanya penutupan penuh pada saluran tenggorokan yang menghalangi aliran udara. Perbedaan kecil antara kesua bahasa tersebut terjadi dalam aspek penyuaraan; di dalam Bahasa Jawa getaran pita suara sangat longgar sehingga menghasilkan suara kendur lebih kendur dibandingkan suara yang seharusnya dihasilkan.

Beberapa contoh transfer konsonan hambat bersuara kendur dari Bahasa Jawa Bahasa Indonesia ditunjukkan pada tabel berikut ini:

\begin{tabular}{|c|c|c|}
\hline \multirow[b]{2}{*}{ Kata } & \multicolumn{2}{|c|}{ Transkripsi Fonetik } \\
\hline & $\begin{array}{c}\text { Bahasa } \\
\text { Indonesia }\end{array}$ & $\begin{array}{c}\text { Transfer } \\
\text { Bahasa Jawa }\end{array}$ \\
\hline bibi & [bi.bi] & [boi.bi] \\
\hline dada & [da.da] & [da.da] \\
\hline gigi & [gi.gi] & [̆gi.g̊i] \\
\hline jaga & [dza.ga] & [d’̊a.g̊a] \\
\hline gigi & [du.ga] & [dò.g̊a] \\
\hline
\end{tabular}

Tabel 3. Transkripsi Fonetik Transfer Konsonan Hambat Bersuara Kendur dari Bahasa Jawa ke Bahasa Indonesia

Dalam transkripsi fonetik diatas, dijelaskan bahwa para subjek penelitian melafalkan kata-kata seperti 'bibi', 'dada', dan 'gigi' dengan akses Jawa. Sebenarnya, tidak banyak perbedaan antara cara pengucapan dalam Bahasa Indonesia dan pengucapan dalam Bahasa Jawa. dalam hal penyuaraan, banyak penutur asli bahasa Jawa menghasilkan bunyi konsonan hambat yang bersifat kendur Transfer terjadi pada konsonan yang memiliki posisi di awal kata dan akhir suku kata seperti /g̊/ pada [g̊i.g̊i] dan / bo/ pada [bi.bi].

Namun, transfer suara kendur tidak terjadi ketika konsonan hambat muncul di akhir kata atau akhir suku kata. Hal ini terjadi lagi-lagi karena persamaan di antara kedua bahasa dimana Bahasa Indonesia dan Bahasa Jawa tidak mengizinkan konsonan bersuara untuk diartikulasikan saat posisi konsonan tersebut berada di akhir kata akhir suku kata.

Berikut adalah tabel yang memuat katakata dengan konsonan hambat yang terletak pada akhir kata ataupun akhir suku kata.

\begin{tabular}{ccc}
\multirow{2}{*}{ Kata } & \multicolumn{2}{c}{ Transkripsi Fonetik } \\
\cline { 2 - 3 } & $\begin{array}{c}\text { Bahasa } \\
\text { Indonesia }\end{array}$ & $\begin{array}{c}\text { Transfer } \\
\text { Bahasa Jawa }\end{array}$ \\
\hline jawab & [dza.wap] & [dza.wap] \\
wujud & [wo.dzot] & [wo.djot] \\
mantab & [man.tap] & [man.tap]
\end{tabular}

Tabel 4. Transkripsi Transfer Fonetik Konsonan Hambat di Akhir Kata

Dari tabel di atas, dapat diamati transkripsi fonetik ketiga kata yang muncul di cerita pendek serta pengucapannya oleh para subjek penelitian. Ternyata tidak ada perbedaan yang ditemukan antara pengucapan standar Bahasa Indonesia dan pengucapan dengan aksen Jawa. Hal tersebut menunjukkan bahwa bahwa kedua bahasa memiliki kemiripan, dimana mereka hanya memungkinkan konsonan hambat tidak bersuara seperti $[\mathrm{p}]$, [t], dan [k] untuk dilafalkan saat berada di akhir kata atau akhir suku kata (syllable coda).

\section{Transfer Konsonan Hambat Glotal Bahasa} Jawa pada Awal Kata atau Akhir Suku Kata

Seperti yang telah dijelaskan sebelumnya, Bahasa Indonesia dan Bahasa Jawa hanya memperbolehkan konsonan hambat tak bersuara untuk berada pada akhir kata. Bahasa Indonesia memiliki tiga konsonan hambat tak bersuara, antara lain $[\mathrm{p}]$, [t], and $[\mathrm{k}]$. Sementara itu, dalam Bahasa Jawa terdapat 
lima macam konsonan hambat tak bersuara, yakni $[\mathrm{p}],[\mathrm{t}],[\mathrm{k}]$, [t] and [?]; dan dari kelima konsonan ini, hanya konsonan retrofleks [t] yang tidak pernah muncul di posisi koda.

Dalam bahasa Jawa, konsonan hambat tanpa suara [k] digunakan untuk mengartikulasikan kata-kata diakhiri dengan 'g' dalam ejaan mereka, sedangkan glottal [?] dihasilkan untuk mengucapkan kata-kata yang berakhir dengan ' $\mathrm{k}$ '. Contohnya antara lain terdapat dalam kata godhog 'merebus' dan pidhek 'menginjak'. Pelafalan kata godhog adalah [g̊o.dok] dimana para penutur Bahasa Jawa menggunakan ' $\mathrm{k}$ ' dalam melafalkan bunyi di akhir kata; sementara itu, pidhek dilafalkan dengan [pı.də?] dimana hurf ' $\mathrm{k}$ ' di akhir kata berubah menjadi glottal [?].

Seperti yang dijelaskan pada contoh diatas, kata yang berhenti glotal [?] sebenarnya menjalani proses tertentu yang disebut debukalisasi. Proses ini adalah proses perubahan suara, di mana lisan konsonan kehilangan tempat asli artikulasi dan memindahkannya ke glotis (Ladfoged dan Maddieson, 1996). Dalam kasus Bahasa Jawa, konsonan velar tidak bersuara $[\mathrm{k}]$ akan terdebukalisasi ke glottal hambat[?] di posisi akhir dari kata atau dalam koda suku kata.

Sementara itu, data penelitian menunjukkan bahwa para subjek penelitian sebagian besar melakukan transfer fonologis dari konsonan velar [k] menuju konsonan glottal [?] saat melafalkan kata-kata dengan huruf ' $\mathrm{k}$ ' di akhir kata. Pelafalan tersebut terangkum dalam tabel berikut ini.

\begin{tabular}{|c|c|c|}
\hline \multirow[b]{2}{*}{ Kata } & \multicolumn{2}{|c|}{ Transkripsi Fonetik } \\
\hline & $\begin{array}{c}\text { Bahasa } \\
\text { Indonesia }\end{array}$ & $\begin{array}{c}\text { Transfer } \\
\text { Bahasa Jawa }\end{array}$ \\
\hline kotak & [ko.tak] & [ko.ta? ] \\
\hline gertak & [gor.tak] & [wo.dzot] \\
\hline retak & [ro.tak] & [g̊or.ta? ] \\
\hline
\end{tabular}

\begin{tabular}{|c|c|c|}
\hline duduk & [dv.dvk] & [do.d $\left.{ }^{d} v \underline{?}\right]$ \\
\hline pojok & [po.dzok] & [рэ.с \\
\hline
\end{tabular}

Tabel 5. Transkripsi Transfer Fonetik Konsinan Glottis di Akhir Kata

Dari tabel diatas dapat diamati bahwa para subjek penelitian melafalkan kata-kata target dengan menggunakan konsonan glottis [?] di akhir kata. Hal tersebut menunjukkan bahwa para sunjek penelitian melakukan transfer fonologis Bahasa Jawa ke Bahasa Indonesia berupa proses 'debuccalization' dari bunyi konsonan velar [k] menuju glottis [?] di akhir kata.

Selain itu, temuan yang menarik lainnya muncul dalam beberapa kata berikut ini:

\begin{tabular}{ccc}
\multirow{2}{*}{ Kata } & \multicolumn{2}{c}{ Transkripsi Fonetik } \\
\cline { 2 - 3 } & $\begin{array}{c}\text { Bahasa } \\
\text { Indonesia }\end{array}$ & $\begin{array}{c}\text { Transfer } \\
\text { Bahasa Jawa }\end{array}$ \\
\hline $\begin{array}{c}\text { desak-an } \\
\text { gertak-an }\end{array}$ & $\begin{array}{c}\text { [də.sa. kan] } \\
\text { [̊̊r.ta.kan] }\end{array}$ & [g̊r.ta?.an]
\end{tabular}

Tabel 6. Transkripsi Transfer Fonetik Konsinan Glottis dalam Kata yang Berimbuhan

Dari kedua diatas ditemukan bahwa tidak ditemukan adanya transfer fonologis pada kata 'desakan'. Seluruh subjek penelitian melafalkannya sesuai dengan kaidah pelafalan Bahasa Indonesia, yakni konsonan velar ' $\mathrm{k}$ ' yang pada kata dasarnya berada di koda/ akhir suku kata, berpindah posisi menjadi awal suku kata/onset saat ditambah akhiran 'an'. Sedangkan pada kata 'gertakan' ditemukan bahwa - meski tidak semua - sebagian besar subjek penelitian melakukan trasfer fonologis dimana bunyi velar $[\mathrm{k}]$ terdebukalisasi menjadi suara glottal. Selain itu, posisi konsonan glottal tersebut tetap berada di akhir suku kata/ coda meskipun ditambah akhiran 'an'. 


\section{Transfer Konsonan Hambat Bilabial}

Selain kedua transfer diatas, transfer fonologis yang ditemukan adalah transfer konsonan hambat bilabial [p] untuk melafalkan bunyi fricative [f].

Temuan dalam penelitian ini menunjukkan bahwa beberapa subjek penelitian melakukan beberapa kali transfer fonologis konsonan tersebut, di antaranya diilustrasikan sebagai berikut.

\begin{tabular}{|c|c|c|}
\hline \multirow[b]{2}{*}{ Kata } & \multicolumn{2}{|c|}{ Transkripsi Fonetik } \\
\hline & $\begin{array}{c}\text { Bahasa } \\
\text { Indonesia }\end{array}$ & $\begin{array}{c}\text { Transfer } \\
\text { Bahasa Jawa }\end{array}$ \\
\hline film & [film] & [pilm] \\
\hline nafas & [nafas] & - \\
\hline $\begin{array}{c}\text { me-lafal- } \\
\text { kan }\end{array}$ & [mə.la.fal.kan] & [mə.la.pal.kan] \\
\hline
\end{tabular}

Tabel 7. Transkripsi Transfer Fonetik Konsinan Bilabial Tak Bersuara [p]

Dari tabel diatas dapat diamati bahwa dari beberapa konsonan frikatif tak bersuara [f], terdapat beberapa subjek penelitian yang melafalkannya dengan bunyi bilabial [p]. Sebenarnya, transfer ini tidak banyak ditemukan (total hanya ada 2 subjek penelitian yang melakukan transfer tersebut); transfer pertama ditemukan dalam kata 'film' dimana dua orang subjek melafalkannya sebagai [pilm]. Sementara itu, pada kata 'melafalkan' terdapat satu subjek yang dikethui melafalkannya dengan menggunakan bunyi bilabial [p]. Meskipun begitu, pada kata 'nafas' tidak ditemukan adanya transfer konsonan Jawa. Dengan kata lain, para subjek penelitian melafalkannya sesuai dengan kaidah Bahasa Indonesia yang benar.

Meskipun begitu, terjadinya beberapa transfer konsonan bilabial menunjukkan sebuah fakta bahwa orang Jawa tidak mengenal konsonan frikatif dalam sistem suaranya. Dengan demikian, beberapa orang Jawa mungkin secara tidak sadar salah mengartikulasikan bunyi gesekan-labio-dental tanpa suara yang ada dalam Bahasa Indonesia sebagai bilabial [p].

\section{KESIMPULAN}

Berdasarkan pembahasan di atas, dapat disimpulkan bahwa Bahasa Indonesia sebagai bahasa resmi Republik Indonesia banyak digunakan bersama dengan bahasa lokal. Oleh sebab itu, tidak mengherankan jika banyak terjadi transfer linguistik antara Bahasa Indonesia dan bahasa daerah; salah satu transfer yang sering ditemukan adalah transfer fonologis, di mana sejumlah penutur bahasa lokal membawa beberapa aspek dari sistem bunyi asli mereka ke dalam Bahasa Indonesia.

Sebagai salah satu suku terbesar di Indonesia, orang-orang Jawa cenderung membawa cara Jawa mereka untuk mengartikulasikan kata-kata dalam Bahasa Indonesia, yang menghasilkan transfer bunyi ujaran. Salah satu kasus yang jelas adalah transfer konsonan hambat Bahasa Jawa ke Bahasa Indonesia; jenis transfer ini antara lain berupa transfer konsonan hambat bersuara kendur, substitusi untuk konsonan berhenti velar [k] menjadi suara glottal Jawa [?] di koda (akhir kata), dan substitusi untuk konsonan frikatif labio-dental [f] menjadi konsonan bilabial tanpa suara [p]. Pada akhirnya, fenomena transfer fonologis seperti ini yang dilakukan oleh pembicara menjadi ciri khas aksen Jawa dalam berbahasa Indonesia.

\section{DAFTAR PUSTAKA}

Celce-Murcia, M.D Brinton \& J. Goodwin. (1996). Teaching pronunciation: A 
reference for teachers of English to speakers of other languages. Cambridge: Cambridge University Press.

Chaer, A. and Agustina. 2004. Sosiolinguistik. Jakarta: Rineka Cipta.

Davenport, M. and Hannahs, S.J. 2010. Introduction to Phonetics and Phonology. $3^{\text {rd }}$ ed. London: Hodder Education.

Dardjowidjojo, Soenjono. 2009. English Phonetics and Phonology for Indonesians. Jakarta: Yayasan Obor Indonesia.

Holmes, J. 1992. An Introduction to Sociolinguistics. New York: Addison Wesley.

Ladfoged, P.,and I. Maddieson. 1996. The Sounds of the World's Languages. Oxford: Blackwell

Mathew, I. (2003). "Errors in Pronunciation of Consonants by Learners of English as a Foreign Language whose First Languages are Indonesian, Gayo, and Acehnese [online]". Monash University Linguistics Papers, 3 (2): 29-44.

Pallawa, A.B and Alam, A.F. (2013) 'A Comparative Analysis between English and Indonesian Phonological Systems'. International Journal of English Language Education, (1): 103-129

Lestiono, R. \& Gusdian, R. (2017a). “Arriving at English Pronunciation by Means of Arabic Consonant Sounds: A Case Study on EFL Students in Indonesian Context" 7 th Kuala Lumpur International Conference on Literature, Humanities, Social Sciences and Education.

Lestiono, R. \& Gusdian, R. (2017b). “Tracing Language Transfer: Patterning English
Pronunciation Through Arabic Sounds In Indonesia". Erudio (Journal of Educational Innovation), 4 (1):1-7.

Scott, J. and A. Pavlenko. (2007). Crosslinguistic Influence in Language and Cognition. New York: Routledge 